Article

\title{
Formulation and Characterization of a Heterotrophic Nitrification-Aerobic Denitrification Synthetic Microbial Community and its Application to Livestock Wastewater Treatment
}

\author{
Qi-yu Zhang ${ }^{1,3}$, Ping Yang ${ }^{2}$, Lai-sheng Liu ${ }^{1, *}$ and Zeng-jin Liu ${ }^{3}$ \\ 1 State Key Laboratory of Simulation and Regulation of River Basin Water Cycle, China Institute of Water \\ Resources and Hydropower Research, Beijing 100038, China; qq125535589@163.com \\ 2 Chongqing RongJi Environmental Technology Co., Ltd., Chongqing 400000, China; liulsh@iwhr.com \\ 3 Institute of Water Resources, North China University of Water Resources and Electric Power, \\ Zhengzhou 450046, China; liuzengjin@ncwu.edu.cn \\ * Correspondence: qq125535589@126.com; Tel.: +86-138-1057-4539
}

Received: 4 December 2019; Accepted: 9 January 2020; Published: 13 January 2020

check for updates

\begin{abstract}
There have been many studies on single strains in wastewater treatment and a new synthetic microbial community was prepared in this study, which provides a reference for the application of heterotrophic nitrification-aerobic denitrification in actual wastewater treatment. The growth period distribution of the composite bacteria was determined by plotting growth curves with different sole nitrogen sources, and the influence of the carbon source, carbon to nitrogen ratio $(\mathrm{C} / \mathrm{N})$ ratio, $\mathrm{pH}$, and temperature on ammonia removal by the composite heterotrophic nitrifying-aerobic denitrifying strain was investigated. The optimal conditions for the heterotrophic nitrification process were sodium citrate as the carbon source, a $\mathrm{C} / \mathrm{N}$ ratio of 10 , a $\mathrm{pH}$ of 7 , and a temperature of $30^{\circ} \mathrm{C}$, and only trace amounts of nitrate and nitrite were observed during the process. When the sequencing batch reactor (SBR) of a pig farm wastewater treatment plant was inoculated with the synthetic microbial community, the average removals of the chemical oxygen demand (COD) and ammonia nitrogen in the effluent were $92.61 \%$ and $20.56 \%$, respectively. From the results, the synthetic microbial community was able to simultaneously perform heterotrophic nitrification-aerobic denitrification indicating great potential for full-scale applications.
\end{abstract}

Keywords: synthetic microbial community; ammonium; heterotrophic nitrification; aerobic denitrification; livestock wastewater

\section{Introduction}

In recent years, the livestock and poultry breeding industry has gradually moved towards specialized and large-scale centralized feeding methods [1]. Compared with traditional distributed breeding, large-scale breeding can significantly improve production efficiency, reduce production costs, and increase economic benefits. The development of large-scale farms has also led to an increase in the amount of livestock and poultry manure runoff, which has placed tremendous pressure on the ecological water environment. Livestock and poultry aquaculture wastewaters contain large amounts of suspended solids, COD, nitrogen, and phosphorus, which cause the eutrophication of water bodies and water pollution. In China, the COD and total nitrogen from the livestock wastewater account for $96 \%$ and $38 \%$ of the total agricultural wastewater, respectively [2]. In addition, the wastewater usually varies considerably in concentration and volume during different seasons or under management processes. Livestock and poultry wastewaters are not a commonly considered pollutant but contain 
abundant resources, including phosphorus and potassium, and the current comprehensive utilization efficiency of livestock and poultry wastewater in China is less than $60 \%[3,4]$. By promoting the utilization of excreta and urine resources, livestock and poultry breeding wastes can become valuable products, such as biogas, organic fertilizer, and reclaimed water, which can effectively alleviate the shortage of agricultural resources in China and control non-point source pollution [5]. Efficient and economical livestock and poultry breeding industry wastewater treatment methods are urgently needed to achieve sustainable development in the modern swine breeding industry and environmental protection [6].

To remove these pollutants, biological methods are preferred in consideration of operational ease and cost [7]. A promising process called biological nitrogen removal treatment can partially and effectively dispose of both the solid and liquid fractions of manure [8]. However, there have been periodic reports on anaerobic ammonium oxidation [9] and aerobic denitrification [10], indicating that although aerobic biological processes have been applied to treat livestock and poultry breeding industry wastewaters effectively, the nitrification-denitrification process has presented challenges due to the long time required, high cost, and difficulty of management [11]. For instance, the cost of floor space and construction for the nitrification-denitrification method is high, and nitrifying bacteria grow slowly, so different conditions are required [12]. The sludge treatment process is cumbersome and easily causes secondary pollution and additional costs. Therefore, a more economical and convenient biological process is necessary [13]. The academic research on livestock and poultry breeding industry wastewaters has mainly aimed to develop a new biological nitrogen removal process and to cultivate superior strains to degrade high-concentration ammonia nitrogen wastewater. Since Robertson et al. discovered that Thisphaera pantotropha had heterotrophic nitrification ability in 1985, researchers have discovered a variety of heterotrophic nitrifying microorganisms with nitrification activity in soil, sludge, lake water, and the deep sea [14]. Studies have found that the heterotrophic nitrification process of T. pantotropha requires energy consumption. Unlike autotrophic nitrifying bacteria, T. pantotropha does not accumulate $\mathrm{NO}_{2}{ }^{-}-\mathrm{N}$ when ammonia is oxidized under aerobic conditions [15]. With the discovery of heterotrophic nitrification-aerobic denitrification bacteria, the theory and technology of biological nitrogen removal have made important breakthroughs. Heterotrophic nitrification-aerobic denitrification has attracted extensive attention as a new type of biological nitrogen removal technology [16]. Compared with traditional biological nitrogen removal, the heterotrophic nitrification-aerobic denitrification process has higher removal efficiency of nitrogen and COD and less nitrous oxide production [17]. This process can realize the unification of nitrification and denitrification in the same time and space, greatly simplifying the process of traditional biological nitrogen removal, and therefore save operating and infrastructure costs [18]. At present, simultaneous nitrification-denitrification technology is a new method of nitrogen removal.

Removal widely occurs in the natural environment and has been successfully realized in oxidation ditches, SBR reactors and other systems [19]. Significantly, studies have shown that changes in factors such as the carbon source, dissolved oxygen, floc characteristics, and sludge concentration affect the reaction process in simultaneous nitrification and denitrification [20]. Studies have shown that many bacteria, actinomycetes, fungi, and even algae have heterotrophic nitrification capabilities. Fungi, such as Aspergillus flavus [21], Penicillium sp. [22], Verticillium sp. [23], Absidia cylindrospora [24], etc. are considered to be the most abundant and most efficient heterotrophic nitrifying microorganisms [25]; lactobacillus, such as Mycobacterium, Nocardia, Micromonospora, and algae, such as Chlorella, salt algae, Phaeodactylum tricornutum [26] also perform heterotrophic nitrification. Furthermore, many heterotrophic bacteria, such as Pseudomonas [27], Alcaligenes sp. [28], Arthrobacter sp. [29], and Alcaligenes faecalis [30] can oxidize ammonia nitrogen to nitrite nitrogen or other states [31].

As mentioned above, many single-species heterotrophic nitrification-aerobic denitrifying microorganisms and their characteristics have been discovered thus far. The synthetic microbial community can couple their efficiency, work together, and have strong environmental adaptability, and their treatment effect is better than that of single microorganisms. Nevertheless, information on 
the combined treatment effects and characteristics of these strains is still very limited. The purpose of this study was to develop an ammonia nitrogen degradation composite composed of heterotrophic nitrification-aerobic denitrifying strains, determine its reaction characteristics and its application in livestock wastewater treatment, and provide an experimental basis and theoretical support for future applications.

\section{Materials and Methods}

\subsection{Media and Reagents}

The beef extract peptone medium consisted of the following components: beef cream $3 \mathrm{~g} \cdot \mathrm{L}^{-1}$, peptone $10 \mathrm{~g} \cdot \mathrm{L}^{-1}$, and $\mathrm{NaCl} 5 \mathrm{~g} \cdot \mathrm{L}^{-1}$. The heterotrophic nitrification medium was composed of $\mathrm{NH}_{4} \mathrm{Cl}$ $0.38 \mathrm{~g} \cdot \mathrm{L}^{-1}, \mathrm{C}_{4} \mathrm{H}_{4} \mathrm{Na}_{2} \mathrm{O}_{4} 5.62 \mathrm{~g} \cdot \mathrm{L}^{-1}$, and $50 \mathrm{~mL}$ Vickers salt solution. The denitrification medium was made up of $\mathrm{KNO}_{3} 0.72 \mathrm{~g} \cdot \mathrm{L}^{-1}, \mathrm{C}_{4} \mathrm{H}_{4} \mathrm{Na}_{2} \mathrm{O}_{4} 2.80 \mathrm{~g} \cdot \mathrm{L}^{-1}, \mathrm{KH}_{2} \mathrm{PO}_{4} 1 \mathrm{~g} \cdot \mathrm{L}^{-1}, \mathrm{MgSO}_{4} \cdot 7 \mathrm{H}_{2} \mathrm{O} 1 \mathrm{~g} \cdot \mathrm{L}^{-1}$, and $2 \mathrm{~mL} / \mathrm{L}$ trace element solution. The BTB (bromothymol blue) medium contained $\mathrm{KNO}_{3} 1 \mathrm{~g} \cdot \mathrm{L}^{-1}$, $\mathrm{L}^{-}$asparagine $1 \mathrm{~g} \cdot \mathrm{L}^{-1}, \mathrm{Na}_{3} \mathrm{C}_{6} \mathrm{H}_{5} \mathrm{O}_{7} \cdot 5 \mathrm{H}_{2} \mathrm{O} 8.50 \mathrm{~g} \cdot \mathrm{L}^{-1}, \mathrm{KH}_{2} \mathrm{PO}_{4} 1 \mathrm{~g} \cdot \mathrm{L}^{-1}, \mathrm{MgSO}_{4} \cdot 7 \mathrm{H}_{2} \mathrm{O} 1 \mathrm{~g} \cdot \mathrm{L}^{-1}, \mathrm{CaCl}_{2} 0.20 \mathrm{~g} \cdot \mathrm{L}^{-1}$, $\mathrm{FeCl}_{3} \cdot 6 \mathrm{H}_{2} \mathrm{O} 0.05 \mathrm{~g} \cdot \mathrm{L}^{-1}$, and $5 \mathrm{~mL} / \mathrm{L} 1 \%$ thymol blue. The LB (Luria ${ }^{-}$Bertani) medium consisted of peptone $10 \mathrm{~g} \cdot \mathrm{L}^{-1}$, yeast extract $5 \mathrm{~g} \cdot \mathrm{L}^{-1}$, and $\mathrm{NaCl} 5 \mathrm{~g} \cdot \mathrm{L}^{-1}$.

The Vickers salt solution contained $\mathrm{KH}_{2} \mathrm{PO}_{4} \cdot 3 \mathrm{H}_{2} \mathrm{O} 6.5 \mathrm{~g} \cdot \mathrm{L}^{-1}, \mathrm{MgSO}_{4} \cdot 7 \mathrm{H}_{2} \mathrm{O} 2.5 \mathrm{~g} \cdot \mathrm{L}^{-1}, \mathrm{NaCl} 2.5 \mathrm{~g} \cdot \mathrm{L}^{-1}$, $\mathrm{FeSO}_{4} \cdot 7 \mathrm{H}_{2} \mathrm{O} 0.05 \mathrm{~g} \cdot \mathrm{L}^{-1}$, and $\mathrm{MnSO}_{4} \cdot 7 \mathrm{H}_{2} \mathrm{O} 0.04 \mathrm{~g} \cdot \mathrm{L}^{-1}$. The trace element solution [32] contained EDTA $50 \mathrm{~g} \cdot \mathrm{L}^{-1}, \mathrm{CaCl}_{2} 5.5 \mathrm{~g} \cdot \mathrm{L}^{-1}, \mathrm{ZnSO}_{4} 2.2 \mathrm{~g} \cdot \mathrm{L}^{-1}, \mathrm{CuSO}_{4} \cdot 5 \mathrm{H}_{2} \mathrm{O} 1.57 \mathrm{~g} \cdot \mathrm{L}^{-1}, \mathrm{FeSO}_{4} \cdot 7 \mathrm{H}_{2} \mathrm{O} 5.0 \mathrm{~g} \cdot \mathrm{L}^{-1}, \mathrm{CoCl}_{2} \cdot 6 \mathrm{H}_{2} \mathrm{O}$ $1.61 \mathrm{~g} \cdot \mathrm{L}^{-1}$, and $\mathrm{MnCl}_{2} \cdot 4 \mathrm{H}_{2} \mathrm{O} 25.06 \mathrm{~g} \cdot \mathrm{L}^{-1}$.

All the media mentioned above were adjusted to an initial $\mathrm{pH}$ of 7.0 to 7.2 and sterilized at $121^{\circ} \mathrm{C}$ and the pressure of $0.12 \mathrm{MPa}$ for $20 \mathrm{~min}$.

\subsection{Screening and Identification of Heterotrophic Nitrifying-Aerobic Denitrifying Strains}

To obtain a high-purity single strain, it was necessary to treat pig farm sludge. Pig farm biogas slurry samples and aerobic sludge samples $(10 \mathrm{~mL})$ were collected, separated, efficiently transferred to a $250 \mathrm{~mL}$ flask containing sterilized $0.90 \% \mathrm{NaCl}$ solution $(90 \mathrm{~mL})$ and glass beads and, then, shaken at $200 \mathrm{rpm}$ to obtain a uniform bacterial suspension. The solution was, then, subjected to gradient dilution, and the resulting solution was inoculated on beef extract peptone medium in an incubator at $30^{\circ} \mathrm{C}$. Through five consecutive enrichment cultures, different single colonies were picked for separation and purification and then inoculated in $100 \mathrm{~mL}$, which was efficiently separated into heterotrophic nitrifying liquid medium. The change in the concentration of ammonia nitrogen in the culture was qualitatively tested to complete the initial screening by observing the colour change of the Nessler reagent. Then, the obtained suspensions of different concentrations were uniformly coated on the surface of BTB medium and placed in a constant-temperature incubator to verify whether there was aerobic-denitrification activity.

The strains obtained by the primary screening were rescreened, and four strains with preferable COD degradation ability and denitrification performance were selected as the target strains and inoculated onto an inclined surface at $4{ }^{\circ} \mathrm{C}$. The screened strains were subjected to Gram staining and observed by optical microscopy [33]. Single colonies were picked and cultured in a liquid medium to $\log$ phase, and the culture solution was used for genome extraction. The 16S rRNA sequences of the strains, amplified by universal primers $27 \mathrm{~F}$ and $1492 \mathrm{R}$, were submitted to NCBI for comparative analysis with GenBank data.

The strains selected from the biogas slurry and the aerobic sludge were prepared at a ratio of 1:1:1:1, which corresponded to the best COD degradation and denitrification performance.

\subsection{Configuring the Synthetic Microbial Community and Measuring Its Growth Curve}

The synthetic microbial community was transferred to NM liquid medium and cultured at $30{ }^{\circ} \mathrm{C}$ and $150 \mathrm{r} / \mathrm{min}$ for $24 \mathrm{~h}$. The ammonia nitrogen removal efficiency reached an average of $91.32 \%$ at $24 \mathrm{~h}$. 
To determine the changes in the growth curve of the complex strain under different nitrogen sources, $\mathrm{NH}_{4} \mathrm{Cl}, \mathrm{KNO}_{3}$, and $\mathrm{NaNO}_{2}$ were selected as the only nitrogen source digestion media. During cultivation, the concentration of the synthetic microbial community, the nitrogen source concentration, and the COD concentration in the reactor were measured. The concentration of the strain was determined by regular measurements of $\mathrm{OD}_{600}$, which is the absorbance of the bacterial suspension at a wavelength of $600 \mathrm{~nm}$. The absorbance and the time were taken as the ordinate and the abscissa, respectively, to plot the growth curves of the synthetic microbial community, which were fitted by exponential growth curves.

\subsection{Effect of Different Factors on Heterotrophic Nitrification-Aerobic Denitrification}

To analyse the effect of different carbon sources on heterotrophic nitrification, glucose, sodium acetate, sodium succinate, and potassium sodium tartrate were selected as electron donors for the synthetic microbial community. In the experiment, the components, other than the carbon source and the nitrogen source in the NM medium, composed the basal medium. For convenience of analysis, the nitrogen source added to the medium was only ammonia nitrogen, and the carbon source to be tested was separately added to maintain a carbon to nitrogen ratio (molecular ratio) of 10 .

A bevelled surface stored in a refrigerator at $4{ }^{\circ} \mathrm{C}$ was used as the source of the strains, and rings were picked into an Erlenmeyer flask containing $100 \mathrm{~mL}$ of $\mathrm{NM}$ fluid medium. The strains were cultured for $24 \mathrm{~h}$ under aerobic shaking at $30^{\circ} \mathrm{C}$ and $150 \mathrm{r} / \mathrm{min}$. The culture conditions were as described above.

To analyse the effect of the $\mathrm{C} / \mathrm{N}$ ratio on heterotrophic nitrification, glucose was the only carbon source, and the fixed nitrogen source concentration was $156.14 \mathrm{mg} \cdot \mathrm{L}^{-1}$ in the experiment. The carbon to nitrogen ratio $(\mathrm{C} / \mathrm{N})$ was changed by adjusting the carbon source concentration so that the $\mathrm{C} / \mathrm{N}$ ratio was $1,4,7,10$, or 13 . The strains were cultured in liquid medium at $30^{\circ} \mathrm{C}$ and $150 \mathrm{r} / \mathrm{min}$ for $24 \mathrm{~h}$ under aerobic shaking.

To determine the optimum environmental $\mathrm{pH}$ or $\mathrm{pH}$ range of the synthetic microbial community, the $\mathrm{pH}$ was set to 5 different values. In this experiment, the effects of $\mathrm{pH}$ values of $5,6,7,8$, and 9 on the growth of the strains were studied.

The heterotrophic nitrification-aerobic denitrification strain was activated in culture medium until reaching $\log$ phase. The bacterial suspension was centrifuged at $8000 \mathrm{rpm}$ for $10 \mathrm{~min}$. The supernatant was removed and resuspended in sterile water, and this procedure was repeated 3 times. The sterilized bacterial suspension was added to a $250 \mathrm{~mL}$ conical flask containing $100 \mathrm{~mL}$ of heterotrophic nitrification medium and cultured at $20^{\circ} \mathrm{C}, 25^{\circ} \mathrm{C}, 30^{\circ} \mathrm{C}, 35^{\circ} \mathrm{C}$, or $40^{\circ} \mathrm{C}$ with a rotating speed of 150 rpm. After culturing in a shaking bed for $24 \mathrm{~h}$, the culture solution was centrifuged to remove the cells, and the supernatant was diluted to determine the ammonia nitrogen concentration.

\subsection{Optimizing the Proportion of Strains Used to Prepare the Synthetic Microbial Community}

The synthetic microbial community was activated in the LB medium to prepare a heterotrophic nitrification-aerobic denitrification medium. According to the above experiment regarding the effects of different factors on heterotrophic nitrification-aerobic denitrification, the culture conditions were set to a carbon source of glucose, the $\mathrm{C} / \mathrm{N}$ ratio of $10, \mathrm{pH}$ of 7 , the temperature of $30^{\circ} \mathrm{C}$, and rotation speed of $150 \mathrm{rpm}$. The ratios of the synthetic microbial community are shown in Table 1 . After $48 \mathrm{~h}$ of culture, the supernatant taken from bacterial fluid centrifuged at $8000 \mathrm{rpm}$ for $5 \mathrm{~min}$ was used to determine the concentration of ammonia nitrogen, and the results were compared with the results for the blank group. 
Table 1. The ratio of the synthetic microbial community.

\begin{tabular}{ccccc}
\hline Ratio & Pseudomonas sp. & Sphingobacterium sp. & Bacillus sp. & Acinetobacter sp. \\
\hline 1 & 1 & 1 & 1 & 1 \\
2 & 1 & 1 & 1 & 2 \\
3 & 1 & 1 & 2 & 2 \\
4 & 1 & 2 & 1 & 2 \\
5 & 1 & 2 & 2 & 1 \\
6 & 1 & 1 & 1 & 3 \\
7 & 1 & 2 & 1 & 3 \\
8 & 1 & 1 & 2 & 3 \\
9 & 1 & 2 & 2 & 3 \\
\hline
\end{tabular}

\subsection{Application of the Synthetic Microbial Community for Pig Farm Wastewater Treatment}

The wastewater came from a pig farm located in Chongqing, China, and the main pollutants contained in the manure sewage of the pig farm were organic matter, suspended matter, and ammonia nitrogen which is a high-concentration component of organic wastewater. The average flow efficiency was $2.5 \mathrm{~m}^{3} / \mathrm{d}$, and the COD concentration and ammonia nitrogen concentration of the influent water were $1.5 \mathrm{~g} \cdot \mathrm{L}^{-1}$ and $1 \mathrm{~g} \cdot \mathrm{L}^{-1}$, respectively. The synthetic microbial community were added to the SBR reactor to remove the COD; the ammonia nitrogen reaction cycle was $12 \mathrm{~h}$, including $9 \mathrm{~h}$ of influent flow and $3 \mathrm{~h}$ of precipitation, and the wastewater was discharged once every two cycles. The length, width, and height of the SBR reactor were 2400, 1000, and $1100 \mathrm{~mm}$, respectively. Sludge loading and the sludge concentration were $0.15 \mathrm{kgCOD} / \mathrm{kgMLSS} \cdot \mathrm{d}$ and $4.0 \mathrm{kgMLSS} / \mathrm{L}$, respectively. The range of the DO (dissolved oxygen) concentration threshold is relatively wide and is not clearly defined. In this experiment, the concentration of DO in the feed water was controlled on average to about 0.001 $\mathrm{g} \cdot \mathrm{L}^{-1}$ to control its stability. Experimental wastewater collection began on August 29, and COD and ammonia removal efficiency monitoring ended on October 10. The startup mode can be divided into asynchronous startup and synchronous startup according to the startup steps. The $\mathrm{pH}$ and temperature of the SBR reactor were approximately $\mathrm{pH} 7$ to 8.2 and $30^{\circ} \mathrm{C}$, respectively. Samples were taken from the tank for the measurement of ammonia and COD in the influent and the effluent, and the data presented in this study were obtained after bioaugmentation.

\subsection{Analytical Methods}

$\mathrm{pH}$ was measured by a PHS-3B precision $\mathrm{pH}$ meter. Ammonium, nitrate, nitrite, and total nitrogen were measured by standard methods [34]. Ammonium was determined by the Nessler's reagent spectrophotometric method [35]. Nitrite was determined by the N-(1-naphthalene)-diaminoethane photometry method. Nitrate was measured by the ultraviolet spectrophotometric method [36], and the total nitrogen was measured by alkaline potassium persulfate digestion-UV spectrophotometry. The COD was measured by a closed reflux colorimetric method. Bacterial growth was monitored by monitoring the optical density at $600 \mathrm{~nm}\left(\mathrm{OD}_{600}\right)$ using a spectrophotometer. The removal efficiency of ammonia nitrogen in the heterotrophic nitrification-aerobic denitrification process was calculated using Equation (1):

$$
\eta_{1}=\left(C_{1}-C_{2}\right) / C_{1} \times 100 \%
$$

where $C_{1}$ is the corresponding concentration of ammonia nitrogen at time $\mathrm{t}_{1}$ in $\mathrm{mg} \cdot \mathrm{L}^{-1}$ and $C_{2}$ is the corresponding concentration of ammonia nitrogen at time $t_{2}$ in $\mathrm{mg} \cdot \mathrm{L}^{-1}$.

The removal efficiency of nitrate in the heterotrophic nitrification-aerobic denitrification process was calculated using Equation (2):

$$
\eta_{2}=\left(N_{1}-N_{2}\right) / N_{1} \times 100 \%
$$


where $N_{1}$ is the corresponding concentration of nitrate at time $t_{3}$ in $\mathrm{mg} \cdot \mathrm{L}^{-1}$ and $N_{2}$ is the corresponding concentration of nitrate at time $\mathrm{t}_{4}$ in $\mathrm{mg} \cdot \mathrm{L}^{-1}$.

The removal efficiency of COD in the heterotrophic nitrification-aerobic denitrification process was calculated using Equation (3):

$$
\eta_{3}=\left(D_{1}-D_{2}\right) / D_{1} \times 100 \%
$$

where $D_{1}$ is the corresponding concentration of COD at time $t_{5}$ in $\mathrm{mg} \cdot \mathrm{L}^{-1}$ and $D_{2}$ is the corresponding concentration of COD at time $\mathrm{t}_{6}$ in $\mathrm{mg} \cdot \mathrm{L}^{-1}$. Larger values of $\eta_{1}, \eta_{2}$, and $\eta_{3}$ implied a higher capability of nitrogen and contaminant removal.

The 16S rRNA gene sequences of the strains were amplified by using the genomic DNA as the template and 16S rRNA universal primers [37]. The purified PCR products were sequenced and compared with the published data in GenBank by using BLAST [38].

\section{Results and Discussion}

\subsection{Isolation and Identification of the Strains}

After the separation, purification, and rescreening of the fifteen strains, four heterotrophic nitrifying strains were picked and named SBR-2, P6, SBR3-2, and SBR-1. The SBR-2 colony was pale yellow with a wrinkled, moist and translucent surface and irregular rectangular edges, and single colonies were short rod shaped. The P6 colony bulged with a shiny surface and milky white and opaque folded edges, and single colonies were rod shaped. The SBR3-2 colony was round and opaque and had a moist surface, and single colonies were long and rod shaped. The SBR-1 colony was yellow with a smooth and moist surface and neat edges, and single colonies were rod shaped.

The genomes of the four heterotrophic nitrifying strains were used as templates to carry out PCR amplification, and partial $16 \mathrm{~S}$ rRNA fragments of the four strains of bacteria were obtained. A neighbour-joining tree based on the 16S rRNA gene sequences was constructed to show the phylogenetic positions of SBR3-2, SBR-1, SBR-2, P6, and representatives of some other related taxa. Bootstrap values (expressed as percentages of 1000 replications) are shown at the branch points; the scale bar represents 0.02 substitutions per nucleotide position. The measured sequences were compared to nucleic acid sequences in the GenBank database. By comparing the results and morphological characteristics mentioned above, strains SBR-2, P6, SBR3-2, and SBR-1 were identified as Pseudomonas sp., Acinetobacter sp., Bacillus sp., and Sphingobacterium sp., respectively, and their sequence similarities were all over 99\%. An NJ tree was constructed using MEGA 7.0.26 (Figure 1).

The synthetic microbial community was prepared from the four strains at a ratio of 1:1:1:1. Under conditions of $30^{\circ} \mathrm{C}$ and $150 \mathrm{r} / \mathrm{min}$ for $24 \mathrm{~h}$, the ammonia nitrogen removal efficiency of the synthetic microbial community reached an average of $91.32 \%$. 


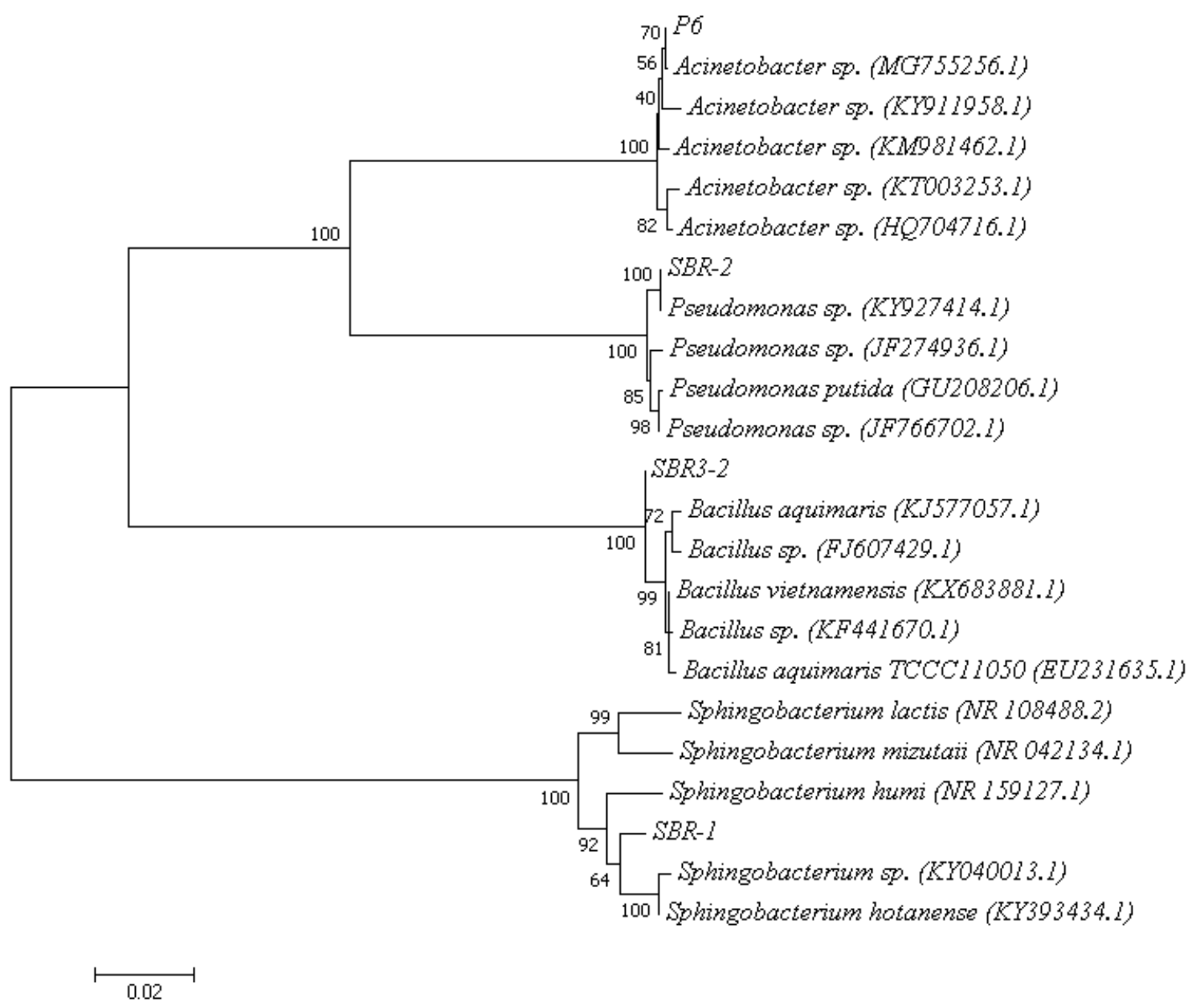

Figure 1. Phylogenetic tree based on $16 \mathrm{~S}$ rDNA sequences of the isolates and related standard bacteria.

\subsection{Growth Curves of Different Unique Nitrogen Sources}

Microbial growth and reproduction mainly proceed via several stages, i.e., the adaptation, logarithmic, stable, and decay stages [39]. To understand the growth cycle of the synthetic microbial community, the growth curve of the synthetic microbial community cultured in nitrification medium with $\mathrm{NH}_{4} \mathrm{Cl}$ as the sole nitrogen source for $24 \mathrm{~h}$ was calculated and is shown in Figure 2; the removal efficiencies of ammonia nitrogen and COD were $98.90 \%$ and $94.46 \%$, respectively. From the change in absorbance at $\mathrm{OD}_{600}$, the synthetic microbial community grew rapidly during the 0 to $4 \mathrm{~h}$ adaptation period, and the strain grew rapidly into the logarithmic growth phase after four hours After $22 \mathrm{~h}$, the strain population reached a maximum and entered the stable phase. The concentration of $\mathrm{NH}_{4}{ }^{+}$ decreased slowly from 0 to $4 \mathrm{~h}$, and the decrease in efficiency at $4 \mathrm{~h}$ was rapid. There was a very small amount of $\mathrm{NO}_{2}{ }^{-}$accumulation during the reaction, while the remaining ammonia nitrogen was partially converted into gaseous nitrogen via the desorption reaction and partially converted into other nitrogen-containing substances in solution.

The growth curve of the synthetic microbial community cultured in nitrification medium with $\mathrm{KNO}_{3}$ as the sole nitrogen source for $24 \mathrm{~h}$ is shown in Figure 3, and the removal efficiencies of ammonia nitrogen and COD were $95.02 \%$ and $65.65 \%$, respectively. The same observation method revealed that the synthetic microbial community was in the adaptation period from 0 to $2 \mathrm{~h}$. After $2 \mathrm{~h}$, the strains grew rapidly into the logarithmic growth phase, and the population was still increasing after $24 \mathrm{~h}$. The concentration of $\mathrm{NO}_{3}{ }^{-}$decreased slowly from 0 to $2 \mathrm{~h}$, and the efficiency of decline increased significantly at $2 \mathrm{~h} ; \mathrm{NO}_{2}{ }^{-}$accumulated throughout the reaction process. This result was in contrast to some heterotrophic nitrification-aerobic denitrification strains, such as LD3 [40], that have a large amount of nitrite accumulation during the reaction. Because nitrite reductase and nitrate reductase 
existed simultaneously in the synthetic microbial community and had high activity, the nitrite nitrogen produced during denitrification was rapidly reduced by the high-activity nitrite reductase [41].

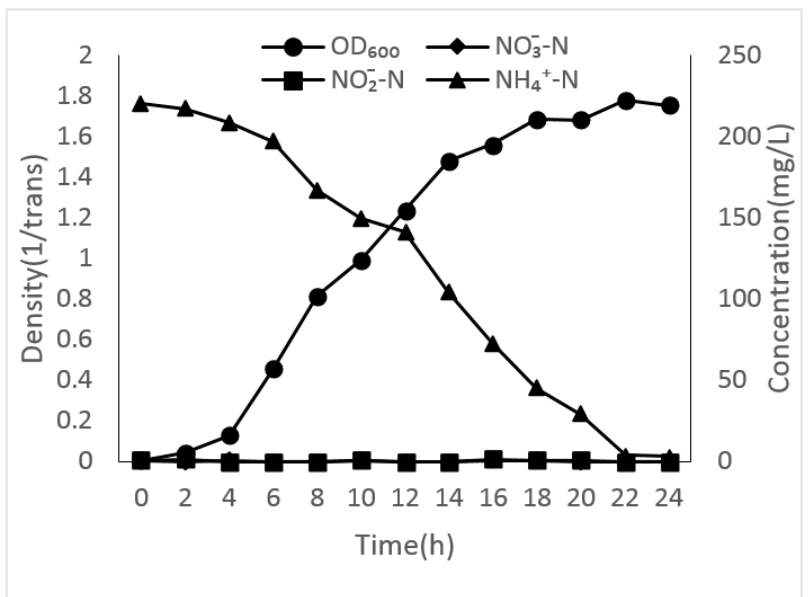

Figure 2. Growth curve of synthetic microbial community with $\mathrm{NH}_{4} \mathrm{Cl}$ as the sole nitrogen source.

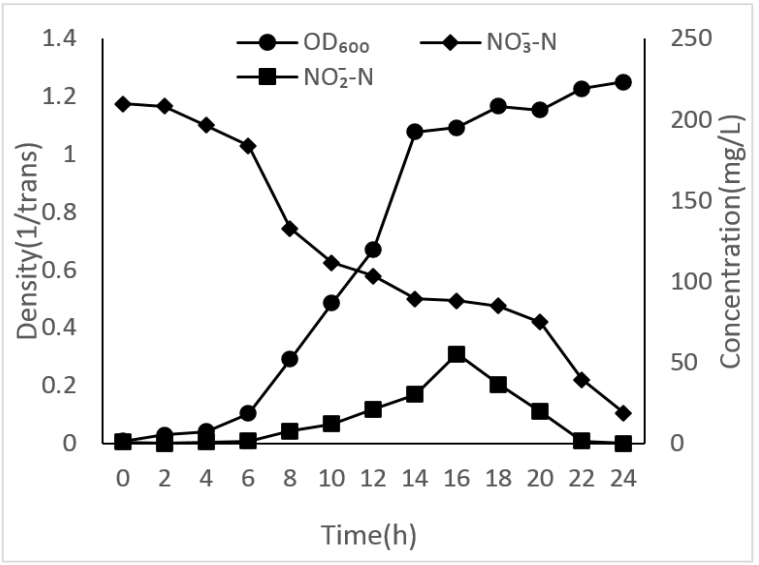

Figure 3. Growth curve of synthetic microbial community with $\mathrm{KNO}_{3}$ as the sole nitrogen source.

The growth curve of the synthetic microbial community cultured in nitrification medium with $\mathrm{NaNO}_{2}$ as the sole nitrogen source for $24 \mathrm{~h}$ is shown in Figure 4, and the removal efficiency of ammonia nitrogen and COD was $98.60 \%$ and $76.45 \%$, respectively. The synthetic microbial community was in the adaptation period from 0 to $2 \mathrm{~h}$. After $2 \mathrm{~h}$, the strain population increased rapidly into the logarithmic growth phase, and the population reached a maximum after $22 \mathrm{~h}$. Although generally, high nitrite concentrations were toxic to the strain and inhibited its growth and metabolism, some strains, such as Y-11, have a certain tolerance to high nitrite [42]. Similarly, the synthetic microbial community showed better tolerance and denitrification capacity.

The results of the batch test indicated that the synthetic microbial community had a good effect on the degradation of nitrogen and the removal of COD in media with different sole nitrogen sources. The use of $\mathrm{NH}_{4} \mathrm{Cl}$ as the sole nitrogen source resulted in a better degradation efficiency, COD removal efficiency, and strain growth than those obtained when using $\mathrm{NaNO}_{2} / \mathrm{KNO}_{3}$ as the nitrogen source. The fact that nitrite had no obvious inhibitory effect on the growth and denitrification of the synthetic microbial community showed good environmental adaptability and potential application in the treatment of nitrite sewage. In summary, the synthetic microbial community can be grown for organic removal under different nitrogen sources, including ammonia nitrogen, nitrate nitrogen, and nitrite nitrogen, and the growth efficiency and organic matter removal efficiency of the synthetic microbial community are affected by the nitrogen source. 


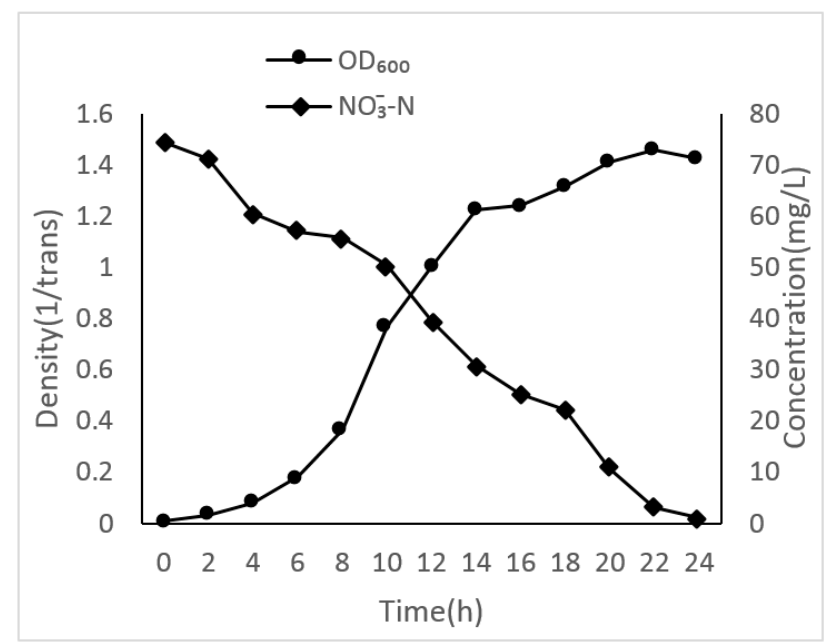

Figure 4. Growth curve of synthetic microbial community with $\mathrm{NaNO}_{2}$ as the sole nitrogen source.

\subsection{Effect of Carbon Source on Heterotrophic Nitrification-Aerobic Denitrification}

The carbon source is not only an energy source for microbial nitrogen removal but also directly or indirectly affects the growth efficiency of microorganisms and the efficiency of nitrogen removal [43]. The fixed nitrogen source concentration $\left(\mathrm{NH}_{4}{ }^{+}-\mathrm{N}\right)$ was $156.14 \mathrm{mg} \cdot \mathrm{L}^{-1}$, and the results in Figure 5 indicate that more carbon sources could be utilized by the synthetic microbial community. In addition, potassium sodium tartrate had a very poor effect as a carbon source, and the removal efficiency of ammonia nitrogen was $98.56 \%, 98.75 \%$, and $99.51 \%$, respectively, when glucose, sodium acetate, and sodium succinate were used as the carbon sources. The effect of sodium tartrate as the sole carbon source is poor because the concentration of different carbon sources in our experiments remains the same. The reaction process using sodium tartrate as a carbon source generally requires a higher carbon source concentration, which reflects the effect deviation. In summary, different carbon sources affect the heterotrophic nitrification ability of the composite bacteria. A suitable carbon source is one of the keys to improving the ammonia nitrogen removal efficiency. The most suitable substance for heterotrophic nitrification by the synthetic microbial community was sodium succinate in this experiment.

\subsection{Effect of the C/N Ratio on Heterotrophic Nitrification-Aerobic Denitrification}

The $\mathrm{NH}_{4}{ }^{+}-\mathrm{N}$ removal percentages were significantly different among $\mathrm{C} / \mathrm{N}$ ratios of one to 13 , as shown in Figure 5. According to the experimental data, the ammonia nitrogen removal efficiency was only $15.92 \%$ when the $\mathrm{C} / \mathrm{N}$ ratio was one, and the main reason was that an insufficient carbon supply could damage both microbial growth and the denitrification of electron donors [44]. As the $\mathrm{C} / \mathrm{N}$ ratio increased, the ammonia nitrogen removal efficiency increased gradually until the $\mathrm{C} / \mathrm{N}$ ratio reached 10, and the ammonia nitrogen removal efficiency reached a maximum at $98.98 \%$. However, when the $\mathrm{C} / \mathrm{N}$ ratio increased from 10 to 13 , the ammonia nitrogen removal efficiency decreased, and the explanation was as follows: the higher carbon-nitrogen ratio made the carbon source content so high that some organic matter was directly embedded into the enzyme structure, affecting enzyme activity [45]. Experiments have shown that the amount of organic carbon plays an essential role in cell growth and denitrification. If the carbon source was insufficient, there was not enough electron flow to provide enough energy for the growth of the cells, and thus the denitrification capacity was relatively low. If the carbon source provided had a much higher content than the demand of the cells, the carbon source was no longer a limiting factor; the growth and metabolic activity of the cells were in a stable phase and can even have undergone reverse growth, and the denitrification capacity was stabilized or decreased. The experimental results showed that the optimal carbon to nitrogen ratio was 10, and the findings for other denitrifying bacteria, such as Vibrio diabolic SF16, seem consistent [46]. 


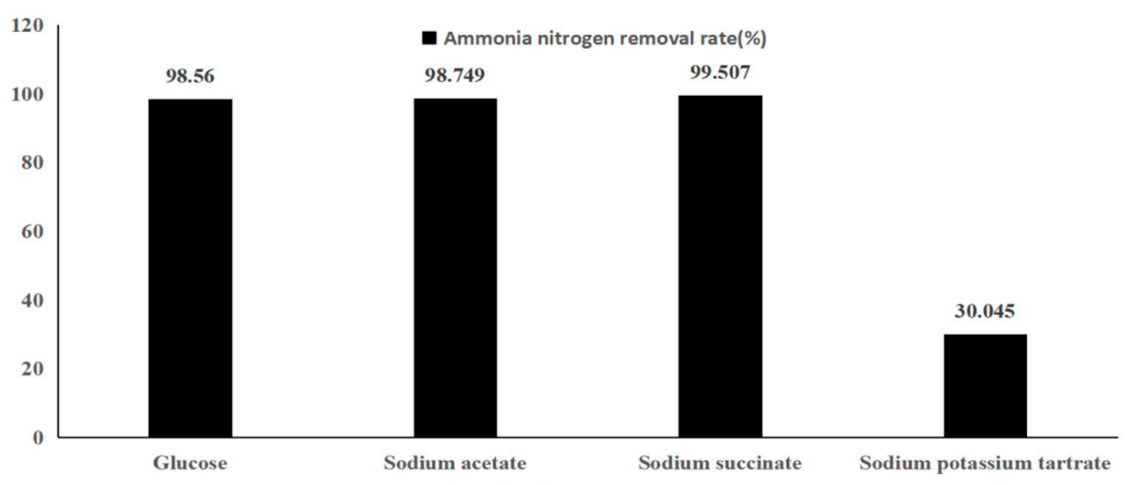

A. Carbon source

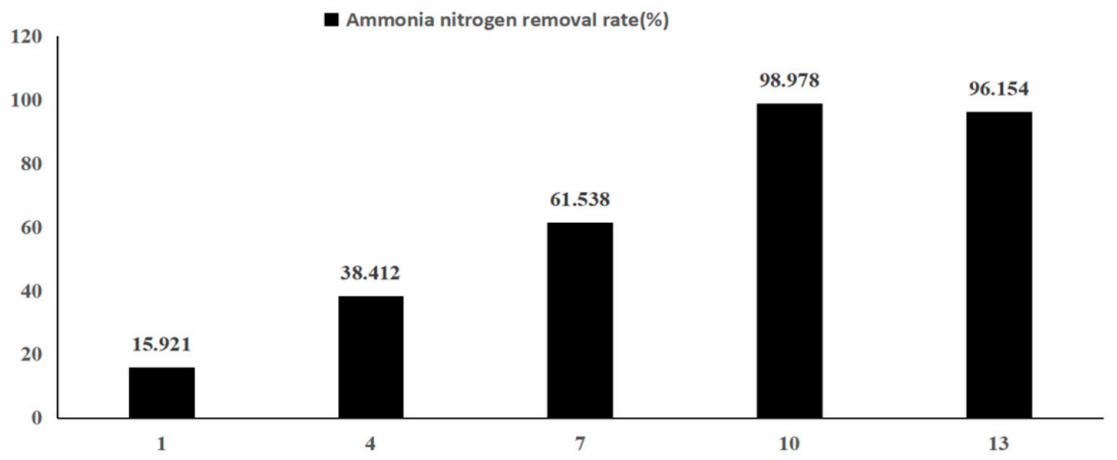

B. $\mathrm{C} / \mathrm{N}$ ratio
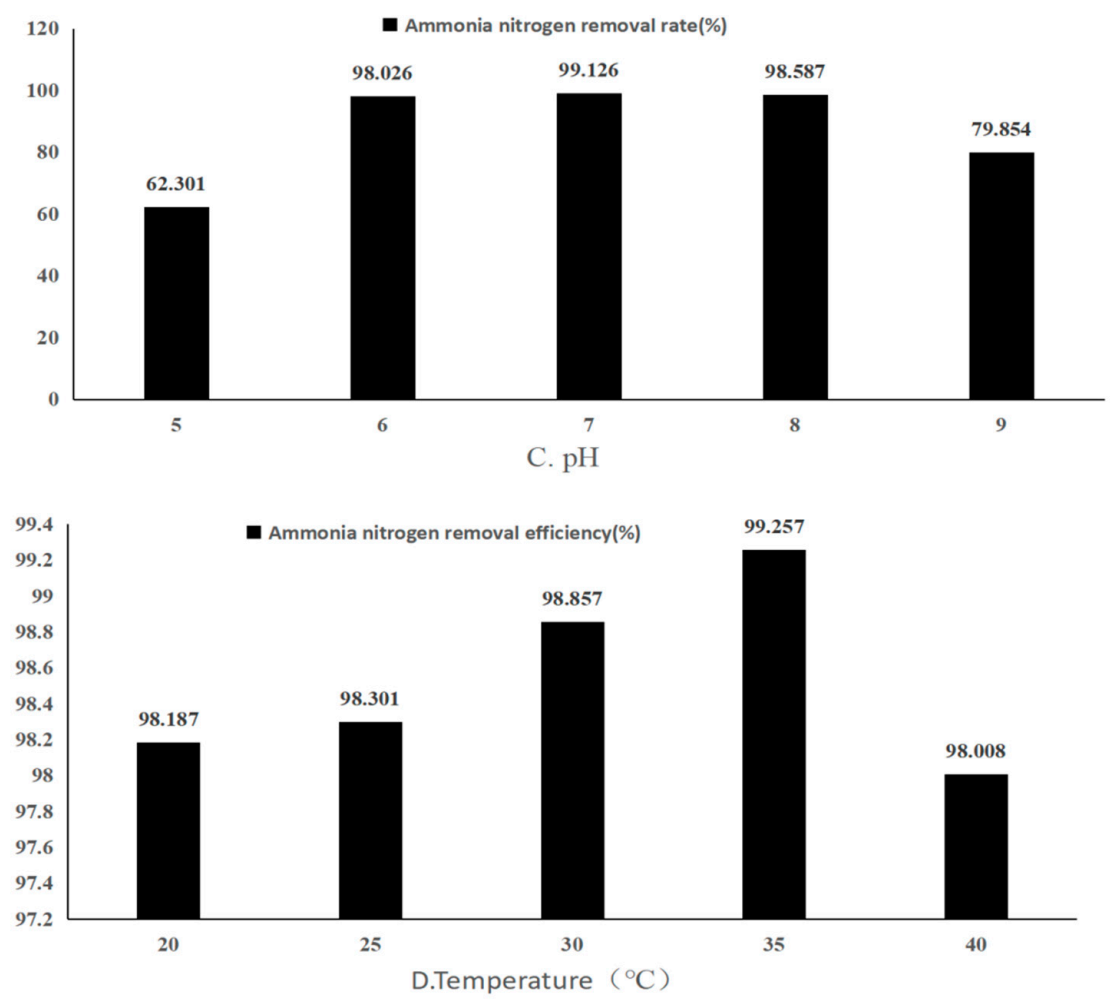

Figure 5. Effect of factors on the growth and nitrification ability of the synthetic microbial community. Carbon source (A), ratio of carbon to nitrogen $(\mathrm{C} / \mathrm{N})(\mathbf{B}), \mathrm{pH}(\mathbf{C})$, and temperature (D).

\subsection{Effect of Changes in $\mathrm{pH}$ on Heterotrophic Nitrification-Aerobic Denitrification}

The $\mathrm{pH}$ in the environment has a significant influence on the life activities of microorganisms. The primary role of $\mathrm{pH}$ is to cause a change in the charge of the cell membrane, thereby affecting the 
absorption of nutrients by the microorganism and affecting the enzyme activity [47]. As shown in Figure 5, the synthetic microbial community demonstrated acid and alkali inhibition at $\mathrm{pH}$ five and $\mathrm{pH}$ nine, respectively. The strain achieved the highest ammonia removal efficiency of $99.13 \%$ at $\mathrm{pH}$ seven, and the ammonia nitrogen removal efficiency of the synthetic microbial community could reach $98 \%$ or more in the range of $\mathrm{pH}$ six to nine.

In general, most heterotrophic nitrification-aerobic denitrification bacteria prefer a neutral or slightly alkaline environment, and the optimal $\mathrm{pH}$ range is six to nine [48]. However, when the culture medium is different, the optimum $\mathrm{pH}$ of heterotrophic nitrifying bacteria will also change. In beef extract peptone medium, the nitrification activity of the strain was not very sensitive, but in glucose-ammonium acetate medium, the nitrification activity was affected by changes in $\mathrm{pH}$.

\subsection{Effect of Changes in Temperature on Heterotrophic Nitrification-Aerobic Denitrification}

The ammonia nitrogen removal efficiency of the synthetic microbial community at different temperatures is shown in Figure 5. In the range $20-40{ }^{\circ} \mathrm{C}$, the denitrification performance of the synthetic microbial community was very good, and a value of $98 \%$ was maintained. Although the synthetic microbial community maintained an ammonia nitrogen removal efficiency of $98.01 \%$, it had a slight decline at $40{ }^{\circ} \mathrm{C}$. What caused this decline was that under high-temperature conditions, the active substances, such as enzymes, in microorganisms are denatured [49], and some cell functions are decreased or even terminated. These results suggested that average temperatures did not play an essential role in the process of heterotrophic nitrification of the synthetic microbial community. Taking cost-effectiveness into consideration, $30^{\circ} \mathrm{C}$ was the most suitable reaction temperature.

\subsection{Optimizing the Proportions of the Strains Used to Prepare the Synthetic Microbial Community}

It can be concluded from Table 2, that the ammonia nitrogen removal efficiency and nitrate removal efficiency dropped significantly upon increasing the proportion of Acinetobacter sp., even to the relative contents corresponding to ratios two, six, and seven. When the ratio of Pseudomonas sp. and Bacillus sp. was kept constant, while increasing the proportion of Sphingobacterium sp. and Acinetobacter sp., the ammonia nitrogen removal rate and nitrate removal efficiency increased, and the maximum value was obtained at ratio number four. This result could have been obtained because the metabolites of a particular strain could have stimulated the growth of other strains or affect their functions, and thus affected the function of the whole system [50]. Comparing experimental group one and experimental group two,, experimental group eight and experimental group nine, a single increase of the ratio of Acinetobacter sp. or a single decrease of the ratio of Pseudomonas sp. is harmful to the entire system. However, from the perspective of the interaction between microorganisms, it is suitable for the whole system to reduce the ratio of Pseudomonas sp. and Bacillus sp. and increase the ratio of Acinetobacter sp. and Sphingobacterium sp. simultaneously. In conclusion, the synthetic microbial community ratio with the highest ammonia nitrogen removal efficiency is Pseudomonas sp.: Sphingobacterium sp.: Bacillus sp.: Acinetobacter sp. = 1:2:1:2 (volume ratio).

Table 2. The effect of the composite ratio of synthetic microbial community on removal efficiency of ammonia nitrogen and nitrate.

\begin{tabular}{ccc}
\hline Ratio & Ammonia Nitrogen Removal Efficiency (\%) & Nitrate Emoval Efficiency (\%) \\
\hline 1 & 91.32 & 98.05 \\
2 & 80.77 & 90.75 \\
3 & 84.33 & 94.35 \\
4 & 96.75 & 99.30 \\
5 & 96.75 & 86.10 \\
6 & 82.48 & 85.50 \\
7 & 77.20 & 85.65 \\
8 & 76.91 & 97.95 \\
9 & 70.49 & 85.65 \\
\hline
\end{tabular}




\subsection{Application of the Synthetic Microbial Community for Pig Farm Wastewater Treatment}

In this application, a bioenhancement scheme was mainly adopted, and the optimized synthetic microbial community was added to the SBR reactor. To enhance the ammonia nitrogen and nitrate removal performance, the reaction conditions were adjusted to the optimal conditions obtained by experimental analysis, i.e., glucose as a carbon source, a $\mathrm{C} / \mathrm{N}$ ratio of 10 , a $\mathrm{pH}$ of 7 , and temperature of $30^{\circ} \mathrm{C}$. The SBR reactor had been operating stably for 40 days, and the average ammonia nitrogen concentration of the effluent water, the average ammonia nitrogen removal efficiency, and the average COD removal efficiency were $42.53 \mathrm{mg} \cdot \mathrm{L}^{-1}, 92.61 \%$, and $76.45 \%$, respectively, as shown in Figures 6 and 7 . To confirm whether ammonia nitrogen eventually became nitrogen gas, the total nitrogen was detected in the effluent. The total nitrogen value per day was slightly higher than that of ammonia nitrogen, which proved that the ammonia-degrading composite agent had indeed played its intended role and completed the biological denitrification process of ammonia from nitrogen to nitrogen. It is worthwhile mentioning that due to the rain, the effluent was diluted, and the ammonia nitrogen in the inlet water was lower than usual. According to the analysis, the excessively high ammonia nitrogen concentration in the inlet water would not be suitable for microbial reactions. After the ammonia nitrogen concentration was appropriately reduced, the removal rate was significantly increased. These results indicate that the use of the synthetic microbial community would result in a significant improvement in the biological nitrogen removal of pig farm wastewater.

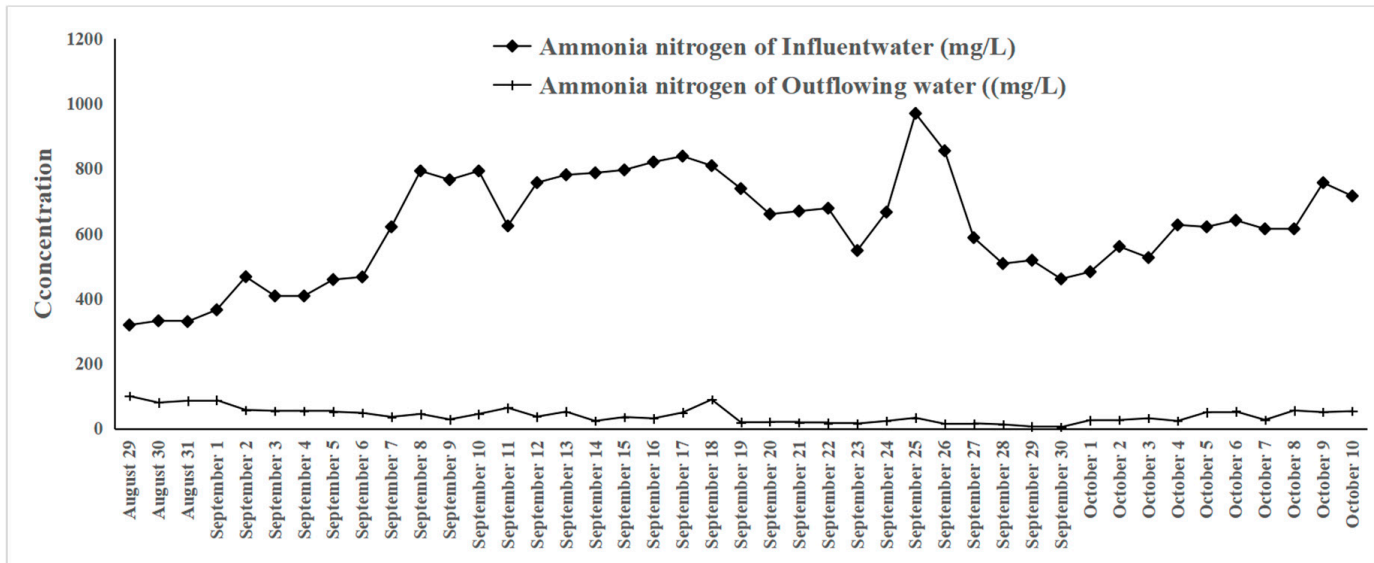

Figure 6. Ammonia nitrogen concentration change in the SBR reactor.

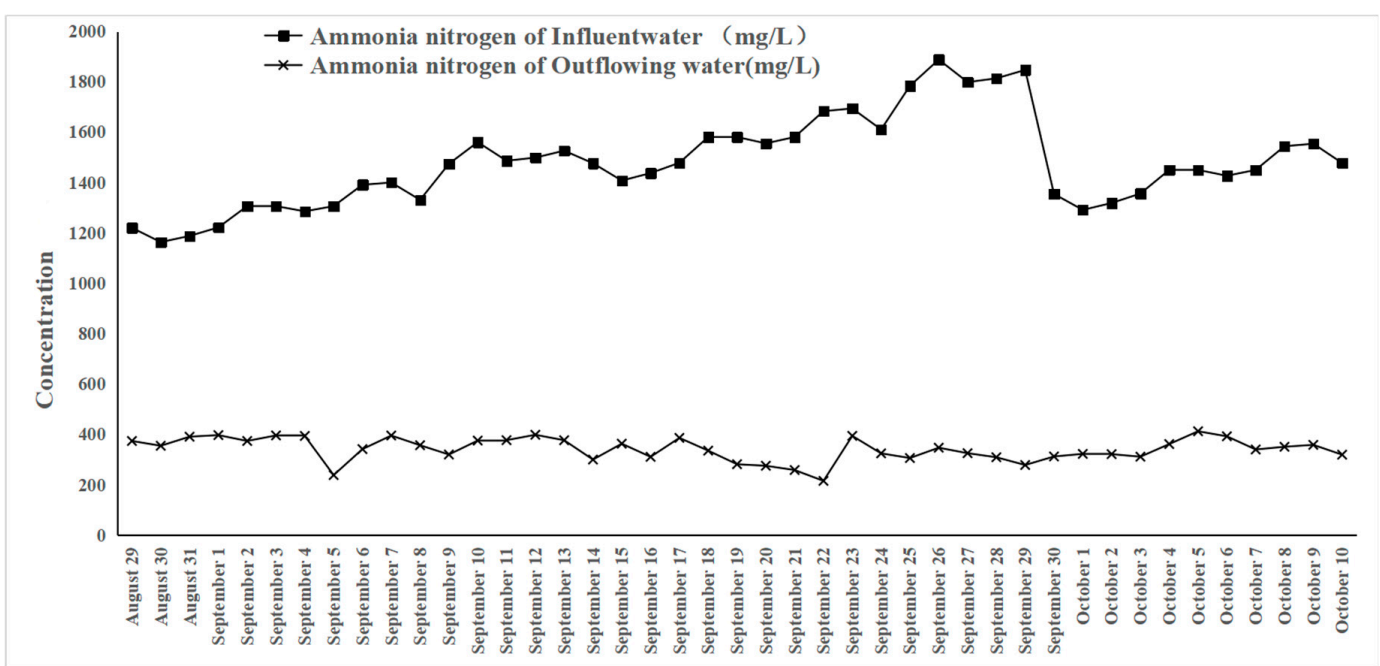

Figure 7. COD concentration change in the SBR reactor. 


\section{Conclusions}

In this study, four heterotrophic nitrification aerobic denitrification strains, SBR2, P6, SBR3-2, and SBR-1, were isolated and identified as Pseudomonas sp., Acinetobacter sp., Bacillus sp., and Sphingobacterium sp., respectively. The synthetic microbial community was composed of the four above strains in a ratio of 1:1:1:1, and its growth curve was drawn under different nitrogen sources. By adjusting the reaction conditions, including the carbon source, carbon to nitrogen ratio, $\mathrm{pH}$, and temperature, and considering the economic benefits and nitrogen removal performance, the reaction conditions of the synthetic microbial community were determined to be sodium succinate as a carbon source at $\mathrm{C} / \mathrm{N}$ of $10, \mathrm{pH}$ of 7 , and $30^{\circ} \mathrm{C}$. The configuration scheme was optimized by adjusting the ratio of the four strains to 1:2:1:2 and detecting their denitrification performance, and the final synthetic microbial community was obtained and applied in pig farm wastewater treatment. In summary, the synthetic microbial community is a promising candidate for extensive application in various pollution control systems, including livestock wastewater and the aquaculture industry, and the next step is to determine the growth characteristics and denitrification performance of the synthetic microbial community under extreme temperature, $\mathrm{pH}$, and ammonia nitrogen concentration values.

Author Contributions: L.-s.L. contributed to the conception of the study; P.Y. contributed significantly to analysis and manuscript preparation; Q.-y.Z. performed the data analyses and wrote the manuscript; Z.-j.L. helped perform the analysis with constructive discussions. All authors have read and agreed to the published version of the manuscript.

Funding: This research was funded by Ministry of Science and Technology of China grant number No. 2018YFC0408103.

Acknowledgments: This research was supported by a grant from the National Key Research and Development Program of China on Domestic Sewage Treatment Technology Development (no. 2018YFC0408103).

Conflicts of Interest: The authors declare no conflict of interest.

\section{References}

1. Peng, L.; Bai, Y. Numerical study of regional environmental carrying capacity for livestock and poultry farming based on planting-breeding balance. J. Environ. Sci. 2013, 25, 1882-1889. [CrossRef]

2. Zheng, T.; Li, P.; Ma, X.; Sun, X.; Wu, C.; Wang, Q.; Gao, M. Pilot-scale multi-level biological contact oxidation system on the treatment of high concentration poultry manure wastewater. Process Saf. Environ. Prot. 2018, 120, 187-194. [CrossRef]

3. Raha, D.; Mahanta, P.; Clarke, M.L. The implementation of decentralised biogas plants in Assam, NE India: The impact and effectiveness of the national biogas and manure management programme. Energy Policy 2014, 68, 80-91. [CrossRef]

4. Chen, R.; Gao, H.Y.; Bo, X.Q.; Shi, R.G.; Zhang, Y.G.; Ma, B.L. Study and application of treatment technology on wastewater from livestock farm. J. Agro-Environ. Sci. 2006, 25, 374-377.

5. Li, Y.; Xu, Z.; Xie, M.; Zhang, B.; Li, G.; Luo, W. Resource recovery from digested manure centrate: Comparison between conventional and aquaporin thin-film composite forward osmosis membranes. J. Membr. Sci. 2019, 593, 1136-1145. [CrossRef]

6. Weia, X.M.; Lina, C.; Duan, N.; Peng, Y.X.; Ye, Z.Y. Application of aerobic biological filter for treating swine farms wastewater. Procedia Environ. Sci. 2010, 2, 1569-1584. [CrossRef]

7. Xu, A.; Yao, J.; Yu, L.; Lv, S.; Wang, J.; Yan, B.; Yu, Z. Mutation of Gluconobacter oxydans and Bacillus megaterium in a two-step process of l-ascorbic acid manufacture by ion beam. Appl. Microbiol. 2004, 96, 1317-1323. [CrossRef]

8. Hellinga, C.; Schellen, A.A.; Mulder, J.W.; van Loosdrecht, M.C.M.; Heijnen, J.J. The sharon process: An innovative method for nitrogen removal from ammonium-rich wastewater. Water Sci. Technol. 1998, 37, 135-142. [CrossRef]

9. Fux, C.; Boehler, M.; Huber, P.; Brunner, I.; Siegrist, H. Biological treatment of ammonium-rich wastewater by partial nitrification and subsequent anaerobic ammonium oxidation (anammox) in a pilot plant. J. Biotechnol. 2002, 99, 295-306. [CrossRef] 
10. Meiberg, J.B.; Bruinenberg, M.P.M.; Harder, W. Effect of dissolved oxygen tension on the metabolism of methylated amines in Hyphomicrobium $\mathrm{X}$ in the absence and presence of nitrate: Evidence for aerobic denitrification. J. Gen. Microbiol. 1980, 120, 453-463. [CrossRef]

11. Cao, L.P.; Zhou, T.; Li, Z.H.; Wang, J.J.; Tang, J.; Ruan, R.; Liu, Y.H. Effect of combining adsorption-stripping treatment with acidification on the growth of Chlorella vulgaris and nutrient removal from swine wastewater. Bioresour. Technol. 2018, 263, 10-16. [CrossRef] [PubMed]

12. Liu, C.; Hou, L.; Liu, M.; Zheng, Y.; Yin, G.; Han, P.; Dong, H.; Gao, J.; Gao, D.; Chang, Y.; et al. Coupling of denitrification and anaerobic ammonium oxidation with nitrification in sediments of the Yangtze Estuary: Importance and controlling factors. Estuar. Coast. Shelf Sci. 2019, 220, 64-72. [CrossRef]

13. Gupta, A.B.; Gupta, S.K. Simultaneous carbon and nitrogen removal from high strength domestic wastewater in an aerobic RBC biofilm. Water Res. 2001, 35, 1714-1722. [CrossRef]

14. Spiller, H.; Dietsh, E.; Kessler, E. Intracellular appearance of nitrite and nitrate in nitrogen-starved cells of Ankistrodesmus braunii. Planta 1976, 129, 175-181. [CrossRef] [PubMed]

15. Robertson, L.A.; Van Niel, E.W.; Torremans, R.A.; Kuenen, J.G. Simultaneous nitrification and denitrification in aerobic chemostat cultures of Thisphaera pantotropha. Appl. Environ. Microbiol. 1988, 54, 2812-2813. [CrossRef]

16. Chen, Q.; Ni, J. Heterotrophic nitrification-aerobic denitrification by novel isolated bacteria. J. Ind. Microbiol. Biotechnol. 2011, 38, 1305-1310. [CrossRef]

17. Yin, M.R.; Wang, P.; Liu, J.N.; Wang, L.; Li, A.B. Screening and identification of a heterotrophic nitrificationaerobic denitrification strain with $\mathrm{N}_{2} \mathrm{O}$ emission control ability. Res. Environ. Sci. 2010, 23, 515-520.

18. Okamoto, K.; Washiyama, K.; Harada, Y. Renovation of an extended aeration plant for simultaneous biology removal of nitrogen and phosphorous using oxic-anaerobic-oxic process. Water Sci. Technol. 1990, 22, 61-68.

19. Kim, J.K.; Park, K.J.; Cho, K.S.; Nam, S.W.; Park, T.J.; Bajpai, R. Aerobic nitrification-denitrification by heterotrophic Bacillus strains. Bioresour. Technol. 2005, 96, 1897-1906. [CrossRef]

20. Gupta, A.B. Thiosphaeern pantotropha-sulphur bacterium capable for simultaneous hetertrophic nitrification and aerobic denitrificatio. Enzyme Microb. Technol. 1997, 21, 589-595. [CrossRef]

21. White, J.P.; Johnson, G.T. Aflatoxin production correlated with nitrification in Aspergillus flavus group species. Mycologia 1982, 74, 718-723. [CrossRef]

22. Killham, K.; Prosser, J.I. Heterotrophic Nitrification; Nitrification IRL Press: Oxford, UK, 1986; Volume 20, pp. 117-126.

23. Lang, E.; Jaqnow, G. Fungi of a forest soil nitrifying at low pH values. FEMS. Microbiol. Ecol. 1986, 38, 257-265. [CrossRef]

24. Stroo, H.F.; Klein, T.M.; Alexander, M. Heterotrophic nitrification in an acid forest soil and by an acid-tolerant fungus. Appl. Environ. Microbiol. 1986, 52, 1107-1111. [CrossRef]

25. Pedersen, H.; Dunkin, K.A.; Firestone, M.K. The relative importance of autotrophic and heterotrophic nitrification in a conifer forest soil as measured by $15 \mathrm{~N}$ tracer and pool dilution techniques. Biogeochemistry 1999, 44, 135-150. [CrossRef]

26. Yu, Y.; Liu, Y.; Han, Y.Y.; Ji, P.; Yang, H.B. The Primary Studies on Ammonia-nitrogen Removal from Fisheries Process Wasterwater by Chlorella vulgaris. Biotechnology 2006, 16, 73-74.

27. Castignetti, D.; Hollocher, T. Heterotrophic nitrification among denitrifiers. Appl. Environ. Microbiol. 1894, 47, 620-623. [CrossRef]

28. Castignetti, D.; Yanong, R.; Ramzinski, R.G. Substrate diversity of an active heterotrophic nitrifier, an Alcaligenes sp. Can. J. Microbiol. 1985, 31, 441-445. [CrossRef]

29. Witze, L.K.; Overbeck, H. Heterotrophic nitrification by Arthrobacter sp. (strain 9006) as influenced by different cultural conditions, growth state and acetate metabolism. Arch. Microbiol. 1979, 122, 137-143. [CrossRef]

30. Anderson, I.C.; Poth, M.; Homstead, J.; Burdige, D. A comparison of $\mathrm{NO}$ and $\mathrm{N}_{2} \mathrm{O}$ production by the autotrophic nitrifier Nitrosomonas europaea and the heterotrophic nitrifier Alcaligenes faecalis. Appl. J. Environ. Microbiol. 1993, 59, 3525-3533. [CrossRef]

31. Kuenen, J.G.; Robertson, L.A. Combined nitrification-dentrification processes. FEMS Microbiol. Rev. 1994, 15, 109-117. [CrossRef]

32. Li, P.; Zheng, Y.L.; Chen, S.L. Identification of an aerobic denitrifying bacterium and its potential application in wastewater treatment. Chin. J. Appl. Environ. Biol. 2005, 11, 600-603. 
33. Xie, J.; Dong, G.; Liu, Z. Microbial sample preparation method by scanning electron microscope. J. Chin. Electron Microsc. Soc. 2005, 24, 440.

34. APHA. Standard Methods for the Examination of Water and Wastewater, 19th ed.; American Public Health Association: Washington, DC, USA, 1995.

35. Zhang, Q. Research on key issues in determination of ammonia nitrogen in water and wastewater by Nessler's reagent spectrophotometry. Environ. Eng. 2009, 27, 85-88.

36. Mahmood, Q.; Zheng, P.; Hayat, Y.; Jin, R.C.; Azim, M.R.; Jilani, G.; Islam, E.; Ahmed, M. Effect of nitrite to sulfide ratios on the performance of anoxic sulfide oxidizing reactor. Arab. J. Sci. Eng. 2009, 34, 45-54.

37. Zhu, Y.Q.; Wei, J.B. Isolation and characterization of an aerobic denitrifier. Microbiology 2009, 36, 616-619.

38. Madueno, L.; Coppotelli, B.M.; Alvarez, H.M.; Morelli, I.S. Isolation and characterization of indigenous soil bacteria for bioaugmentation of PAH contaminated soil of semiarid Patagonia. Argent. Int. Biodeterior. Biodegrad. 2011, 65, 345-351. [CrossRef]

39. Yates, G.T.; Smotzer, T. On the lag phase and initial decline of microbial growth curves. J. Theor. Biol. 2007, 244, 511-517. [CrossRef]

40. Lianjun, W.Y.; Yabian, Y.Q. Screening aerobic denitrifiers from soil and study on characteristics of denitrification. Chin. J. Environ. Eng. 2011, 5, 1902-1906.

41. Zuo, W.; Harbin, D. An Aerobic Denitrifier Screened Identification and Denitrification Characteristic. Master's Thesis, Harbin Institute of Technology, Harbin, China, 2006.

42. He, T.; Xu, Y.; Li, Z. Identification and characterization of a hypothermia nitrite bacterium Pseudomonas tolaasii Y-11. Acta Microbiol. Sin. 2018, 55, 992-1000.

43. Lee, D.U.; Lee, I.S.; Choi, Y.D.; Bae, J.H. Effects of external carbon source and empty bed contact time on simultaneous heterotrophic and sulfur-utilizing autotrophic denitrification. Process Biochem. 2001, 36, 1215-1224. [CrossRef]

44. Huang, X.F.; Li, W.G.; Zhang, D.Y.; Qin, W. Ammonium removal by a novel oligotrophic Acinetobacter sp. Y16 capable of heterotrophic nitrification aerobic denitrification at low temperature. Bioresour. Technol. 2013, 146, 44-50. [CrossRef] [PubMed]

45. Song, Y.J.; Li, Y.; Liu, Y.X.; He, W.L. Effect of carbon and nitrogen sources on nitrogen removal by a heterotrophic nitrification-aerobic denitrification strain Y1. Acta Sci. Circum. 2013, 33, 2491-2497.

46. Duan, J.M.; Fang, H.D.; Su, B.; Chen, J.F.; Lin, J.M. Characterization of a halophilic heterotrophic nitrification-aerobic denitrification bacterium and its application on treatment of saline wastewater. Bioresour. Technol. 2015, 179, 421-428. [CrossRef]

47. Ren, Y.X.; Yang, L.; Liang, X. The characteristics of a novel heterotrophic nitrifying and aerobic denitrifying bacterium, Acinetobacter junii YB. Bioresour. Technol. 2014, 71, 1-9. [CrossRef] [PubMed]

48. Zhang, Q.L.; Liu, Y.; Ai, G.M.; Miao, L.L.; Zheng, H.Y.; Liu, Z.P. The characteristics of a novel heterotrophic nitrification-aerobic denitrification bacterium, Bacillus methylotrophicus strain L7. Bioresour. Technol. 2012, 108, 35-44. [CrossRef] [PubMed]

49. Kim, D.J.; Lee, D.I.; Keller, J. Effect of temperature and free ammonia on nitrification and nitrite accumulation in landfill leachate and analysis of its nitrifying bacterial community by FISH. Bioresour. Technol. 2006, 97, 459-468. [CrossRef]

50. Rolf, A. Inhibition of Staphylococcus aureus and spheroplasts of Gram-negative bacteria by an antagonistic compound produced by a strain of Lactobacillus plantarum. Int. J. Food Microbiol. 1986, 3, 149-160.

(C) 2020 by the authors. Licensee MDPI, Basel, Switzerland. This article is an open access article distributed under the terms and conditions of the Creative Commons Attribution (CC BY) license (http://creativecommons.org/licenses/by/4.0/). 